\title{
Introduction: S.NET and Nanoethics
}

\author{
Sarah R. Davies • Arianna Ferrari
}

Received: 18 October 2012 / Accepted: 19 October 2012 /Published online: 1 November 2012

(C) Springer Science+Business Media Dordrecht 2012

This special issue is perhaps an unusual one. Rather than focusing on a specific theme or topic, it takes as its inspiration the activities of the Society for the Social Study of Nanoscience and Emerging Technologies (S.NET) and in particular its 2011 Annual Meeting. The papers which comprise this collection therefore pick up on the concepts and themes discussed at this meeting. Rather than having a common focus or question, their key feature is the degree to which they are eclectic: they explore topics from governmentality to ontology; ethics-in-practice to visions and expectations. This special issue therefore seeks to celebrate - as does S.NET itself - the diversity of a field which explores new and emerging technologies from a wide range of methodologies, frameworks and disciplinary positions.

S.NET aims to promote intellectual exchange around and understanding of nanotechnologies and other new and emerging technologies. As the Society's name suggests, its emphasis is firmly on locating such emerging technologies within a social context, and on critically

\section{S. R. Davies $(\bowtie)$}

Department of Media, Cognition and Communication, University of Copenhagen,

Copenhagen, Denmark

e-mail: dxq327@hum.ku.dk

\section{A. Ferrari}

Karlsruhe Institute of Technology, Institute for Technology Assessment and Systems Analysis, Karlsruhe, Germany interrogating their development within different national, cultural and technoscientific locations. It is therefore an international organisation, as reflected in the geography of its annual meetings: the 2011 meeting, held in Tempe (USA), was its third, after previous meetings in Seattle (USA) and Darmstadt (Germany). (The 2012 meeting recently took place in Enschede, in the Netherlands.) The Tempe meeting confirmed the vitality of the organisation and of the intellectual streams that meet within it: it saw a continued rise in the number of participants from around the world, increased engagement from non-academic actors (such as research organisations, industry, and policy actors and a number of NGOs), and the representation of new-for S.NETapproaches and perspectives on the relationships between technological development and society. Keynote speakers (who included Geri Augusto, Brown University; Ann Bostrom, University of Washington; Noela Invernizzi, Federal University of Parana; and Nick Pidgeon, Cardiff University) spoke on topics from geoengineering to public perceptions of nanotechnology and the nano industry workforce.

One recurring theme was the notion of the futurea concept which is inevitably a constitutive element of discussions of technological development, but which can be too readily ignored or taken for granted (Selin [1]). For instance, two conference sessions, coordinated by Christopher Coenen (Institute for Technology Assessment and Systems Analysis) and Simone Arnaldi (University of Padua), were devoted to discussion of the governance of ethically controversial 
emergent technologies. With contributions from philosophy, law, and sociology, an interdisciplinary and interactive discussion emerged in which the focus was the relevance of visions, expectations and images for technological development. Here, then, imaginations of the future play an active role in constituting governance decisions. Discussion also explored the role that ethical reflections - and in particular ethics as a professionalised discipline - themselves play in political and social discourse on emergent technoscience. Again, the emphasis was on the way in which interrogations of a 'future', even in the form of ethical reflection upon it, function to shape it.

How to deal with 'the future' was also widely discussed in other parts of the meeting. Ulrike Felt (University of Vienna), for example, explored the different ways the future can be thematised. She called for the development of a 'grammar' of future scenarios, each with different utilities, depending on the material practices, social situations, and economic and political conditions coupled to them. Kornelia Konrad (University of Twente) analyzed the role of expectations in the governance of new technologies and suggested the need for further development of the sociology of expectations within anticipatory processes such as 'Foresight Technology Assessment'. And Alfred Nordmann (TU Darmstadt) criticized the 'design' of the future within technology assessment, arguing for a research agenda that leaves behind the illusion of a direct effect of current decisions on future technological developments. The future, he suggested, should not be seen as an object of design by processes that seek to control it; instead, we need to interrogate the present and to view the future as a projection of current wishes and needs [2]. Such an approach would also put pay to speculation about the future of technology, humanity and society in the form of so-called 'speculative ethics' [3].

If the future was a focus for S.NET 2011 then so was the present, in the shape of reflections upon the society's research object. An implicit question permeated discussion: was nano-hype over? And if so, what would that mean for scholarship around the social study of nanotechnology? In fact, a glance at the meeting's program shows that the question answers itself: it was clear that presenters were taking the techniques and lessons learned from the critical study of nanotechnology and applying them to other technoscientitific domains. Thus Steve Rayner (Oxford University) and Nick Pidgeon
(Cardiff University) both spoke about geoengineering in their keynote talks, while Marianne Boenink (University of Twente) organised a set of panel discussions around the emerging discipline of 'translational research'. Others spoke about environmental issues, biotechnology, or systems biology (for instance). As S.NET develops and grows, then, it seems clear that it will continue to apply the insights gained from the study of nanotechnology-insights which include significant progress in the theory and practice of the governance turn, public engagement, and ethical reflectionto other technological domains.

The 2011 S.NET meeting, then, very consciously showcased a wide range of perspectives on emerging technologies, drawing an audience from the academy, policy, and industry. This diversity is not to suggest, however, that there were no common positions or concepts - that there was nothing, other than a shared interest in new and emerging technologies, uniting participants. A number of key themes were evident throughout the meeting: an emergent broadening of the society's activities beyond nanotechnology to synthetic biology, geoengineering, translational research, and converging technologies; the sense that it is important to reflect on the social contexts and values that frame technological developments and visions; the importance of referring to concrete governance scenarios and already existent frameworks, especially in the legal domain, in order to fruitfully discuss the implications of future technological domains; an emphasis on the discourse of responsibility and on working through how emerging technologies might be developed in line with this.

These themes are also evident in the papers that comprise this special issue. These four papers, which were either initially presented at or inspired by S.NET 2011, come from four very different intellectual perspectives and cover very different ground. Ferrari, Coenen and Grunwald, for instance, explore the difficult relationship between technological visions and ethics in current discourse on human enhancement. Analyzing the debate on pharmacological cognitive enhancement (PCE), they argue that the lack of empirical evidence on the safety and efficacy of the substances used and on the social relevance of the phenomenon has led to speculation and hype and thus to problematic ethical discussion. They suggest that a comprehensive normative evaluation of technological visions should contain, besides ethical analysis, elements of vision assessment (which 
include, inter alia, actor analysis and analyses of worldviews), and an examination of the social and political structures in which these visions arise and develop.

If Ferrari et al. take a largely conceptual approach, Rider, Bennett and Wetmore might be understood as applying this focus on the interrogation of ethical visions to an empirical analysis. They are similarly concerned with frameworks for thinking about the ethics of future-oriented technologies - outlining two different approaches for thinking about 'responsibility', and combining these to create a new synthetic framework-but also in using these to understood practitioner articulations of responsibility. Using interviews with a local nanotechnology 'innovation community' (including academic scientists, attorneys, investors, entrepeneurs, and media actors), they find that these 'real world' articulations of responsibility tend to be located in particular corners of their conceptual framework, leading to something of a lack of reflection in particular areas. Ultimately, they note, "actors within the sampled community are infrequently considering why they are pursuing technological solutions". While this may not be a problem, given the presence of such wider reflection in areas such as policy-and indeed the activities of S.NET itself - it is always worth observing and interrogating such lacunae.

Sonia Desmoulin is also concerned with the presence and regulation of ethical reflection. She asks whether the rise of converging technologies (particularly in its 'Nano-Bio-Info-Cogno', or NBIC, form) calls for a change in the way in which French law should approach the regulation of new and emerging technologies. Precisely because of the vague and indecisive nature of such technological convergence, there are two ways for French legal scholars such as herself to react: either to conduct a case by case analysis, which is inevitably destined to remain too narrow (by "plunging into details", she writes, "one gains in accuracy and rigor but there is a risk of losing the overall picture"), or to acquire a broader view, which runs the risk of itself becoming implicated in the rhetoric of technoscientific promises. A third approach is necessary but is, at least in the current environment, hindered by the difficulty of actually identifying what is under discussion in the claims, promises and hype that circulate this field.

Finally, Luigi Pellizzoni offers a treatment of the ethical in governance regimes around technoscience. Using an approach that draws from Foucauldian scholarship on governmentality and from critiques of contemporary neoliberalism, he argues that ethics can be viewed as a fulcrum point through which regulation is managed, governance is enacted, and a fundamentally instrumental rationality imposed. Ethics, he writes, "is framed as the equivalent in the normative realm of the function that 'sound science' performs in the realm of facts". Pellizzoni's discussion offers a powerful reminder that, whilst nanotechnology and other emerging technologies do present ethical issues that should be considered, our own practices as scholars of ethics, participatory democracy or regulation also require interrogation. It is easy for our work to become embroiled in, and constitutive of, the very regimes that we seek to examine.

These four papers, then, might be understood as united in their interrogation of the (nano)ethical. Whilst the authors write from diverse (and at times opposing) perspectives, and take sites as different as French law and Arizonan nano industry as their cases, all are concerned with better understanding how nanoethics is, could and should be constituted in worlds of practice and academe. In so doing they are certainly drawing on the spirit and foci of S.NET - as well as of this journal, and our wider community of scholarship around nanotechnology's social, ethical and legal ramifications.

\section{References}

1. Selin C (2008) The sociology of the future: tracing stories of technology and time. Sociol Compass 2(6):1878-1895

2. Nordmann A (2010) A forensics of wishing: technology assessment in the age of technoscience. Poiesis Praxis 7 (1-2):5-15

3. Nordmann A, Rip A (2009) Mind the Gap Revisited. Nat Nano 4(5):273-274 